\title{
Associação entre brucelose e ocorrência de abortamentos em bovinos do Estado do Espírito Santo - Nota Prévia
}

\author{
Association between brucellosis and occurrence of abortions in bovine from the Espírito \\ Santo State, Southeast region of Brazil
}

\section{Sérgio Santos de AZEVEDO ${ }^{1}$; José Soares FERREIRA NETO²; Fernando FERREIRA²; Ricardo Augusto DIAS $^{2}$; Marcos AMAKU ${ }^{2}$; Sílvio Arruda VASCONCELLOS ${ }^{2}$}

\author{
${ }^{1}$ Unidade Acadêmica de Medicina Veterinária do Centro de Saúde e Tecnologia Rural da Universidade Federal de Campina \\ Grande, Patos - PB, Brasil \\ ${ }_{2}^{2}$ Departamento de Medicina Veterinária Preventiva e Saúde Animal da Faculdade de Medicina Veterinária e Zootecnia da \\ Universidade de São Paulo, São Paulo - SP, Brasil
}

\begin{abstract}
Resumo
Foi conduzido um estudo para verificar a possível associação entre ocorrência de abortamentos e soroprevalência de brucelose bovina no Estado do Espírito Santo. Foram analisados 5.201 soros de fêmeas bovinas com idade igual ou superior a 24 meses, provenientes de 571 propriedades, sorteadas dentro de duas regiões do Estado (região 1, norte do Estado; região 2, sul do Estado). Para o diagnóstico sorológico da brucelose bovina, foi utilizado o teste do Antígeno Acidificado Tamponado (AAT) como prova de triagem e o teste do 2-mercaptoetanol como prova confirmatória. Uma propriedade foi considerada foco quando apresentou pelo menos um animal soropositivo. Nas duas regiões e no Estado todo, a prevalência de brucelose foi significativamente maior nas propriedades que relataram a ocorrência de abortamentos e nos animais com histórico de abortamentos $(\mathrm{P}<0,05)$, indicando que a Brucella abortus pode ser uma causa importante de abortamentos no Estado do Espírito Santo.
\end{abstract}

Palavras-chave: Brucelose animal. Epidemiologia (controle). Sorologia. Perdas reprodutivas.

\begin{abstract}
A survey to investigate the possible association between the occurrence of abortion and seroprevalence of bovine brucellosis in the State of Espírito Santo, Southeast region of Brazil, was carried out. A total of 5,201 sera from cows $\geq 24$ months-old from 571 herds, drawn in two regions of the state (region 1, north of the state, region 2, south of the state), were analyzed. For serological diagnosis of bovine brucellosis the Rose Bengal Test (RBT) was applied as a screening test and the 2-mercaptoethanol test as a confirmatory test. A herd was considered focus when presented at least one seropositive animal. In both regions and in the State, prevalence of brucellosis was significantly higher in herds that have reported the occurrence of abortions and in animals with a history of abortions $(\mathrm{P}<0.05)$, indicating that Brucella abortus may be an important cause of abortions in the State of Espírito Santo.
\end{abstract}

Keywords: Animal brucellosis. Epidemiology (control). Serology. Reproductive losses.

A brucelose bovina é doença bacteriana de evolução crônica e caráter granulomatoso difuso, caracterizada pela infecção de células do sistema mononuclear fagocitário, causada por uma bactéria intracelular facultativa integrante do gênero Brucella, e apresentando-se em todo o mundo como problema sanitário e econômico ${ }^{1}$. O principal agente etiológico é a Brucella abortus, cujo biotipo 1 é o mais frequente ${ }^{2}$. Bovinos sexualmente maduros, especialmente vacas prenhes, são mais susceptíveis à infecção. Nestes animais, a infecção é usualmente crônica, com a persistência do agente no útero e nos linfonodos. O sinal clínico predominante nas vacas gestantes é o abortamento, que ocorre em torno do sétimo mês de gestação. $\mathrm{O}$ abortamento ocorre com grande freqência na primeira gestação pós-infecção, mas em decorrência do desenvolvimento da imunidade celular, é pouco frequente em uma segunda, e muito raro nas subsequentes. Estima-

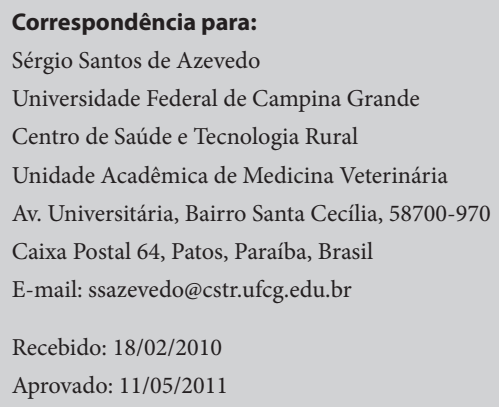


se que a doença é responsável por $15 \%$ de perda de bezerros em decorrência de abortamentos ${ }^{2}$.

O objetivo do presente trabalho foi verificar a possível associação entre ocorrência de abortamentos e soroprevalência de brucelose bovina no Estado do Espírito Santo.

Foram utilizados o banco de soro e o banco de dados oriundos do estudo da situação epidemiológica da brucelose bovina no Estado do Espírito Santo, realizado como parte do Programa Nacional de Controle e Erradicação da Brucelose e Tuberculose ${ }^{3}$ e planejado pelo Ministério da Agricultura, Pecuária e Abastecimento (MAPA) em colaboração com o Instituto de Defesa Agropecuária e Florestal do Espírito Santo (IDAF-ES). Nesse estudo foram utilizadas fêmeas bovinas com idade igual ou superior a 24 meses, provenientes de propriedades sorteadas dentro de duas regiões do estado (região 1, norte do Estado; região 2, sul do Estado), no período de 12 de janeiro de 2002 a 24 de janeiro de 2003. Em cada região, estimou-se a prevalência de propriedades infectadas pela brucelose bovina e a de animais soropositivos por meio de um estudo amostral em dois estágios, para detectar focos de brucelose. No primeiro estágio, sorteou-se, de forma aleatória, número pré-estabelecido de propriedades com atividade reprodutiva (unidades primárias de amostragem) e, no segundo, um número préestabelecido de fêmeas bovinas com idade igual ou superior a 24 meses (unidades secundárias de amostragem). Em propriedades com até 99 fêmeas com idade igual ou superior a 24 meses foram sorteadas dez delas e naquelas com 100 ou mais, 15 delas. No total, foram analisados 5.201 soros de fêmeas bovinas com idade igual ou superior a 24 meses, provenientes de 571 propriedades.

Para o diagnóstico sorológico da brucelose, o teste do Antígeno Acidificado Tamponado (AAT) foi utilizado como prova de triagem e os soros que reagiram positivamente no mesmo foram submetidos à prova confirmatória do 2-mercaptoetanol (2-ME) ${ }^{4}$. Paralelamente ao teste do 2-ME, foi realizado o teste de Soroaglutinação Lenta em Tubos (SALT).
Para o cálculo da prevalência de focos (propriedades com pelo menos um animal soropositivo) no Estado, foi feita a composição das prevalências estratificadas pela ocorrência e não ocorrência de abortamentos por região de forma ponderada. Para o cálculo das prevalências nos animais estratificadas pelo histórico de abortamento dos animais dentro das duas regiões do estado, foi feita uma ponderação, considerando o quanto cada fêmea representou no total de fêmeas ( $\geq 24$ meses) dentro de cada propriedade. Para o cálculo da prevalência nos animais para o Estado, além do tratamento referido no período anterior, também foi feita a ponderação considerando o quanto o total de fêmeas ( $\geq 24$ meses) das propriedades amostradas representaram na população de fêmeas ( $\geq 24$ meses) de cada região. A verificação da possível associação entre ocorrência de abortamentos e soroprevalência de brucelose bovina foi efetuada com o teste de qui-quadrado, com nível de significância de $5 \%{ }^{5}$, utilizando o programa EpiInfo 6.04.

Com relação à prevalência de focos de brucelose estratificada pela ocorrência de abortamentos nas propriedades, foi constatado que a prevalência de focos foi de $15,6 \%$ em propriedades com ocorrência de abortamentos e de $4,6 \%$ em propriedades sem ocorrência de abortamentos, na região 1 (Tabela 1). $\mathrm{Na}$ região 2, as frequências foram de $20,3 \%$ e $8,4 \%$, respectivamente. No estado, as prevalências de foco foram de $18,1 \%$ em propriedades com ocorrência de abortamentos e de $6,7 \%$ em propriedades sem ocorrência de abortamentos. Na região 1, a prevalência de animais soropositivos foi de $26,0 \%$ em animais com histórico de abortamento e de 3,1\% em animais sem histórico de abortamento (Tabela 2). As frequências, para a região 2 , foram de $13,4 \%$ e $3,7 \%$, respectivamente. No estado, as prevalências de animais soropositivos foram de $21,2 \% \mathrm{em}$ animais com histórico de abortamentos e de 3,3\% em animais sem histórico de abortamentos. 
Tabela 1 - Prevalência de focos de brucelose bovina em propriedades rurais do Estado do Espírito Santo com e sem ocorrência de abortamentos segundo a região do Estado, no período de 12 de janeiro de 2002 a 24 de janeiro de 2003

\begin{tabular}{|c|c|c|c|c|c|c|c|}
\hline \multirow{3}{*}{ Região } & \multirow{3}{*}{$\begin{array}{c}\text { № total de } \\
\text { propriedades }\end{array}$} & \multicolumn{6}{|c|}{ Ocorrência de abortamentos } \\
\hline & & \multicolumn{3}{|c|}{ Sim } & \multicolumn{3}{|c|}{ Não } \\
\hline & & № de Focos & $\begin{array}{l}\text { Prevalência } \\
\text { (\%) }\end{array}$ & IC $95 \%$ & № de Focos & $\begin{array}{l}\text { Prevalência } \\
\text { (\%) }\end{array}$ & IC $95 \%$ \\
\hline 1 & 10670 & $10 / 64$ & 15,6 & {$[8,6-26,7]$} & $10 / 218$ & 4,6 & {$[2,5-8,3]$} \\
\hline 2 & 12585 & $13 / 64$ & 20,3 & {$[12,2-32,0]$} & $19 / 225$ & 8,4 & {$[5,4-12,9]$} \\
\hline Estado & 23255 & $23 / 128$ & $18,1^{\mathrm{a}}$ & {$[12,3-25,9]$} & $29 / 443$ & $6,7^{b}$ & {$[4,7-9,5]$} \\
\hline
\end{tabular}

Efeitos do desenho amostral $={ }^{\mathrm{a}} 1,041 \mathrm{e}^{\mathrm{b}} 1,051$

Tabela 2 - Prevalência de brucelose em fêmeas bovinas com idade $\geq$ a 24 meses com e sem histórico de abortamento no Estado do Espírito Santo segundo a região do Estado, no período de 12 de janeiro de 2002 a 24 de janeiro de 2003

\begin{tabular}{|c|c|c|c|c|c|c|c|}
\hline \multirow{3}{*}{ Região } & \multirow{3}{*}{$\begin{array}{l}\text { № total de } \\
\text { fêmeas } \geq 24 \\
\text { meses }\end{array}$} & \multicolumn{6}{|c|}{ Histórico de abortamento } \\
\hline & & \multicolumn{3}{|c|}{ Sim } & \multicolumn{3}{|c|}{ Não } \\
\hline & & $\begin{array}{c}\text { № de } \\
\text { fêmeas } \\
\text { positivas }\end{array}$ & $\begin{array}{l}\text { Prevalência } \\
\text { (\%) }\end{array}$ & IC $95 \%$ & $\begin{array}{c}\text { № de } \\
\text { fêmeas } \\
\text { positivas }\end{array}$ & $\begin{array}{l}\text { Prevalência } \\
\text { (\%) }\end{array}$ & IC $95 \%$ \\
\hline 1 & 468563 & $4 / 38$ & 26,0 & {$[7,1-61,9]$} & $30 / 2603$ & 3,1 & {$[1,1-8,4]$} \\
\hline 2 & 297117 & $9 / 63$ & 13,4 & {$[5,5-29,3]$} & $43 / 2497$ & 3,7 & {$[2,1-6,5]$} \\
\hline Estado & 765680 & $13 / 101$ & $21,2^{\mathrm{a}}$ & {$[8,1-45,1]$} & $73 / 5100$ & $3,3^{\mathrm{b}}$ & {$[1,8-6,2]$} \\
\hline
\end{tabular}

Efeitos do desenho amostral $={ }^{\mathrm{a}} 3,77 \mathrm{e}^{\mathrm{b}} 18,56$

Analisando-se os resultados das tabelas 1 e 2, constatou-se a existência de diferenças significativas entre as propriedades com e sem ocorrência de abortamentos na região $1(\mathrm{p}=0,005)$, região $2(\mathrm{p}=0,014)$ e em todo o estado $(\mathrm{p}<0,001)$, e entre animais com e sem histórico de abortamentos também na região $1(\mathrm{p}=$ $0,001)$, região $2(\mathrm{p}=0,009)$ e Estado $(\mathrm{p}<0,001)$, em relação à prevalência de brucelose.

Algumas frequências apresentadas nas tabelas $1 \mathrm{e}$ 2 não correspondem ao valor relativo esperado. Isso é devido à influência exercida pelo desenho amostral no tamanho da amostra, isto é, de que forma as unidades amostrais são selecionadas. Na prevalência de fêmeas soropositivas para a brucelose bovina no estado, o desenho amostral empregado foi a amostragem de grupo em dois estágios. Do ponto de vista prático e operacional, este tipo de desenho é o mais simples, no entanto, a imprecisão na estimativa da prevalência é maior do que quando se usa uma amostragem simples aleatória. Exemplos desta imprecisão foi o efeito do desenho no cálculo da prevalência de animais soropositivos em fêmeas sem histórico de abortamento, cujo valor foi 18,56 . O efeito do desenho pode ser definido como sendo a razão entre as imprecisões associadas à estimativa de um parâmetro sob dois desenhos amostrais ${ }^{6}$, ou seja, na estimativa da prevalência de fêmeas soropositivas, é a razão entre a variância da estimativa na amostragem de grupo e a variância da estimativa assumindo-se que os dados viessem de uma amostra simples aleatória. Tomando-se como base o efeito do desenho de 18,56, significa dizer que a variância foi estimada como sendo 18,56 vezes a variância para uma amostra simples aleatória, ou seja, o intervalo de confiança obtido é 18,56 vezes o intervalo de con- 
fiança caso a amostragem utilizada fosse a simples aleatória. Assim, o efeito do desenho funciona como um "preço" a ser pago pela facilitação da tarefa ao se investigar apenas os grupos sorteados, aumentando a imprecisão na estimativa da prevalência devido às possíveis correlações das unidades amostrais dentro e entre os grupos.

Não existem dados sobre a ocorrência de abortamentos na população de fêmeas bovinas do Estado do Espírito Santo, bem como da associação deste transtorno com a prevalência de brucelose. Nas duas regiões e no estado todo, a prevalência de brucelose foi significativamente maior nas propriedades que relataram a ocorrência de abortamentos e nos animais com histórico de abortamentos, indicando que a Brucella abortus pode ser uma causa importante de abortamentos no Estado do Espírito Santo. Resultados similares foram observados por Darwesh e Benkirane ${ }^{7}$ na Síria, e por Silva, Dangolla e Kulachelvy ${ }^{8}$ no Sri Lanka.

Apesar da grande variedade de agentes infecciosos desencadeadores de abortamentos em bovinos, a Brucella abortus é considerada uma das principais causas. Campero et al. ${ }^{9}$, na Argentina, isolaram Brucella abortus de 28 (35\%) fetos abortados de um total de 80 fetos examinados. Brucella abortus e Leptospira spp. foram os agentes bacterianos mais frequentemente isolados em 257 fetos abortados examinados no Instituto Biológico de São Paulo, no período de 1985 a $1992^{10}$.

O controle e erradicação da brucelose bovina deve ser encarado como processo que atinge resultados a

\section{Referências}

1.PAULIN, L. M.; FERREIRA NETO, J. S. A experiência brasileira no combate à brucelose bovina. Jaboticabal: Funep, 2003. 154 p.

2. ACHA, P. N.; SZYFRES, B. Zoonosis y enfermedades transmisibles comunes al hombre y a los animales. 3 . ed. Washington: Organización Panamericana de la Salud/Oficina Sanitária Panamericana/Oficina Regional de la Organización Mundial de la Salud, 2001. v. 1, 398 p.

3. AZEVEDO, S. S.; FERREIRA NETO, J. S.; DIAS, R. A.; FERREIRA, F.; AMAKU, M.; FIGUEIREDO, V. C. F.; LÔBO, J. R.; GONCALVES, V. S. P.; SOUZA, A. C.; VASCONCELLOS, S. A. Situaçã̃o epidemiológica da brucelose bovina no Estado do longo prazo, e compreende medidas que são aplicadas de acordo com a ocorrência e distribuição da infecção. A notificação de abortamentos e envio de materiais para cultivo bacteriano com o intuito de se realizar o diagnóstico etiológico devem ser considerados como medidas de controle. England et al. ${ }^{11}$ construíram um modelo de transmissão para descrever a dinâmica da difusão da brucelose bovina na Grã-Bretanha no caso de importação de pelo menos um animal infectado e observaram que, sob o regime de periodicidade de testes diagnósticos empregados para a vigilância epidemiológica da doença na região, a probabilidade de difusão da infecção antes da detecção pelos testes diagnósticos aumentaria de $63 \%$ para $97 \%$ com a ausência de uma estratégia de notificação de abortamentos. Observaram ainda que, para rebanhos leiteiros, o tempo necessário para a difusão da infecção em cinco rebanhos seria de dois anos caso houvesse a notificação de abortamentos; sem a notificação de abortamentos, esse tempo cairia para três meses. Dessa maneira, sugere-se que no Estado do Espírito Santo, aonde foi constatada associação entre prevalência de brucelose bovina e ocorrência de abortamentos, a notificação de abortamentos e envio de materiais para diagnóstico etiológico sejam adotados com o intuito de evitar, ou pelo menos minimizar, a difusão da infecção.

\section{Agradecimentos}

À FAPESP, ao CNPq, ao IDAF-ES e ao MAPA pelo apoio financeiro.

Espírito Santo. Arquivo Brasileiro de Medicina Veterinária e Zootecnia, v. 61, p. 19-26, 2009.

4. BRASIL. Ministério da Agricultura, Pecuária e Abastecimento. Departamento de Defesa Animal. Programa Nacional de Controle e Erradicação da Brucelose e Tuberculose (PNCEBT) - Manual técnico. Brasília: MS, 2004. 132 p.

5.ZAR, J. H. Biostatistical analysis. 4. ed. Upper Saddle River: Prentice Hall, 1999. 663 p.

6. LUIZ, R. R.; MAGNANINI, M. M. F. O tamanho da amostra em investigações epidemiológicas. In: MEDRONHO, R. A.; 
CARVALHO, D. M.; BLOCH, K. V.; LUIZ, R. R.; WERNECK, G. L. Epidemiologia. São Paulo: Atheneu, 2005. p. 295-307.

7.DARWESH, M.; BENKIRANE, A. Field investigations of brucellosis in cattle and small ruminants in Syria, 1990-1996. Revue Scientifique et Technique Office International des Epizooties, v. 20, n. 3, p. 769-775, 2001.

8. SILVA, I.; DANGOLLA, A.; KULACHELVY, K. Seroepidemiology of Brucella abortus infection in bovids in Sri Lanka. Preventive Veterinary Medicine, v. 46, n. 1, p. 51-59, 2000.

9. CAMPERO, C. M.; MOORE, D. P.; ODEÓN, A. C.; CIPOLLA, A. L.; ODRIOZOLA, E. Aetiology of bovine abortion in
Argentina. Veterinary Research Communications, v. 27, n. 5, p. 359-369, 2003.

10.GENOVEZ, M. E.; SCARCELLI, E.; ROJAS, S.; GIORGI, W.; KANETO, C. N. Isolamentos bacterianos de fetos abortados bovinos examinados no Instituto Biológico de São Paulo, no período de 1985 a 1992. Brazilian Journal of Veterinary Research and Animal Science, v. 30, n. 2, p. 107-112, 1993.

11.ENGLAND, T.; KELLY, L.; JONES, R. D.; MACMILLAN, A.; WOOLDRIDGE, M. A simulation model of brucellosis spread in British cattle under several testing regimes. Preventive Veterinary Medicine, v. 63, p. 63-73, 2004. 